\title{
PEMAHAMAN HAK DAN KEWAJIBAN MASYARAKAT DESA TANJUNG KARANG
}

\author{
Ardiansah $^{1}$, Silm Oktapani ${ }^{2 *}$ \\ ${ }^{1,2)}$ Program Studi Ilmu Hukum, Fakultas Hukum, Universitas Lancang Kuning \\ e-mail : ardiansah@unilak.ac.id
}

\begin{abstract}
Abstrak
Telah diberlakukannya Undang-Undang tentang Desa adalah sebagai pedoman terciptanya tatanan kehidupan yang serasi, selaras dan seimbang serta memudahkan tercapainya suatu tujuan di pedesaan. Tentu saja menjadi dasar dalam pengenaan sanksi atau hukuman. Penyelenggaraan pengabdian ini bertujuan untuk dapat melihat sejauhmana masyarakat Desa mengetahui dan memahami Undang-Undang Desa Nomor 6 Tahun 2014 tentang Desa, terkhususnya mengenai hak dan kewajiban masyarakat Desa. Metode pengabdian kepada masyarakat ini dalam bentuk ceramah. Sebelum dan sesudah penyuluhan, peserta diminta mengisi kuisioner pre-test dan post-test. Berdasarkan hasil kegiatan tampak bahwa meningkat pemahaman masyarakat mengenai hak dan kewajiban sebagai masyarakat Desa berdasarkan Undang-Undang Nomor 6 Tahun 2014 . Hal ini terlihat dari hasil penilaian kuisioner dan tanggapan para peserta. Peserta telah dapat memahami akan hak dan kewajibannya sebagai masyarakat Desa serta dapat membedakan antara hak dan kewajiban sebagai masyarakat Desa berdasarkan UndangUndang Nomor 6 Tahun 2014 tentang Desa. Kegiatan seperti ini perlu dilakukan secara rutin agar masyarakat lebih memahami ketentuan dari setiap Undang-Undang.
\end{abstract}

Kata Kunci : Hak, Kewajiban, Masyarakat Desa.

\begin{abstract}
Abstrak
The enactment of the Law on Villages is a guideline for the creation of a harmonious, harmonious and complete order of life and the achievement of objectives in the villages. Certainly be the basis in the imposition of punishment or punishment. The implementation of this service is intended to be able to see the extent to which the public is aware of and ratified Law Number 6 of 2014 concerning Villages, especially regarding the rights and needs of the Village community. Community service methods in the form of lectures. Before and after counseling, participants fill out pre-test and post-test questionnaires. Based on the results seen from an increase in community understanding of the rights and needs of the village community based on Law Number 6 of 2014. This can be seen from the results of the Questionnaire and the responses of the participants. Participants can question their rights and obligations as a village community to distinguish between community rights and obligations based on Law Number 6 of 2014 concerning Villages. Activities like this need to be done routinely so that people need more provisions from each law.
\end{abstract}

Keywords : Rights, Obligations, Village Communities.

\section{PENDAHULUAN}

Penyelenggaraan pemerintahan desa mengalami perubahan dari masa ke masa. Pada masa reformasi telah lahir Undang-Undang Nomor 22 Tahun 1999 tentang Pemerintahan Daerah, yang mengatur daerah otonom dan desa dalam satu paket. UndangUndang Pemerintah Daerah tersebut tidak hanya membawa perubahan di daerah, akan 
tetapi namun juga memberikan landasan bagi perubahan yang mendasar di desa (Kushandajani, 2018).

Undang-Undang Nomor 6 Tahun 2014 tentang Desa (selanjutnya disingkat Undang-Undang Desa) disahkan pada tanggal 15 Januari 2014. Pada saat mengesahan undang-undang tersebut, hampir semua fraksi di DPR telah membahas kegagalan peraturan lama dan perlunya peraturan baru tentang Desa. Peraturan baru ini menjadi koreksi terhadap kesalahan-kesalahan aturan lama sekali. Pengesahan Undang-undang Desa ini merupakan otokritik terhadap peraturan lama tentang desa yang selama ini terkesan tidak serius dan kurang berkomitmen terhadap standar pembangunan di desa. (Timotius, 2018).

Terbitnya Undang-Undang Desa memberikan harapan baru dan konsep baru tentang kebijakan tata kelola desa. Undang-Undang Desa ini tidak lagi menempatkan desa pada bagian belakang, akan tetapi pada terdepan Indonesia. Undang Undang Desa telah memberikan ruang berkembangnya prinsip keberagaman dan mengangkat hak dan kedaualatan desa yang selama ini terpinggirkan karena diposisikan sebagai sub-nasional (Ra'is, 2017).

Pada bagian lain, terbitnya Undang-Undang Desa secara membawa perubahan terhadap tata pemerintahan desa di tingkat Pemerintahan daerah. Bila sebelumnya pengaturan desa terdapat dalam konstruksi otonomi yang menitikberatkan pada kabupaten dan kota, Undang-Undang Desa meletakkan pengaturan desa sebagai bagian konsep desentralisasi dan otonomi (Phahlevy, 2016).

Kelahiran Undang-Undang Desa menandai babak baru penyelenggaraan kebijakan desentralisasi di tingkat pemerintahan terendah. Dengan berlakunya Undang-Undang Desa, maka Desa menjadi lebih kuat legitimasinya. Di samping itu, Undang-Undang Desa memberikan sejumlah hak-hak mendasar baik bagi pemerintahan desa maupun bagi masyarakat desa, ditambah sejumlah hak dan kewajiban pemerintah desa dan masyarakat desa (Aritonang, 2015).

Bangunan hukum Undang-Undang Desa memuat hal yang baru. Pertama, UndangUndang Desa lahir lebih dahulu dibandingkan Undang-Undang Nomor 23 Tahun 2014 tentang Pemerintahan Daerah. Kedua, terbitnya Undang-Undang Desa merefleksikan penghargaan terhadap desa. Ketiga, keberagaman karakteristik dan jenis desa tetap memberikan pengakuan dan jaminan terhadap keberadaan kesatuan masyarakat hukum dan kesatuan masyarakat hukum adat beserta hak tradisionalnya (Kushandajani, 2015).

Undang-Undang Desa yang baru memiliki misi mulia. Dengan pemberlakuan Undang-Undang Desa ini, negara berupaya menyediakan dana untuk pembangunan, melindungi dan memberdayakan masyarakat agar desa menjadi kuat, maju, mandiri, dan 
demokratis, sehinggga memperkuat fondasi dalam menjalankan pemerintahan desa dan pembangunan menuju masyarakat yang adil, makmur, dan sejahtera (Eko, 2014).

Pemberlakuan Undang-Undang dalam perjalanan pemerintahan mewajibkan kepada Camat, Lurah, Kepala Desa, dan perangkat kelurahan/desa sebagai pemimpin yang berhadapan secara langsung dengan masyarakat kelurahan/desa harus saling bekerjasama dan terintegrasi untuk mengawal dan menjalankan Undang-Undang Desa ini dan peraturan perundang-undangan lainnya dalam rangka mewujudkan kesejahteraan ( Pitono, 2016).

Undang-Undang Desa mengatur tentang tugas dan fungsi Pemerintahan Desa. Di samping itu, Undang-Undang Desa juga mengatur tentang hak dan kewajiban masyarakat desa. Pasal 68 Undang-Undang Desa mengatur lima poin penting mengenai hak dan kewajiban masyarakat desa (Sugiman, 2018).

Undang-Undang Desa terdiri dari 16 Bab dan 122 Pasal, antara lain mengatur kedudukan dan jenis desa, penataan desa, kewenangan desa, penyelenggaraan pemerintahan desa, hak dan kewajiban desa dan masyarakat, keuangan dan aset desa, pembangunan desa dan pembangunan kawasan perdesaan, Badan Usaha Milik Desa, kerjasama desa, serta pembinaan dan pengawasan ( Mardison, 2012). Oleh karena itu, agar Undang-Undang Desa berjalan efektif, maka perlu partisipasi aktif masyarakat dalam pembangunan desa (Theresia, 2014).

Berdasarkan hal tersebut, penting diberikan penyuluhan hukum kepada masyarakat desa mengenai Undang-Undang Desa terutama mengenai substansi hak dan kewajiban masyarakat desa. Apabila pemahaman masyarakat desa meningkat mengenai hak dan kewajibannya, maka diharapkan masyarakat bisa berperan aktif dalam pembangunan desa.

\section{METODE}

Adapun metode pelaksanaan kegiatan Pengabdian Kepada Masyarakat ini ialah penyuluhan hukum. Dengan rincian metode sebagai berikut: 1) Penyuluhan dengan cara pemaparan mengenai hak dan kewajiban masyarakat desa berdasarkan Undang-Undang Nomor 6 Tahun 2014 Tentang Desa. 2) Dialog interaktif, dalam hal ini peserta sebagai subjek yang dapat memberikan ulasan terkait dengan hak dan kewajiban masyarakat desa. Penyuluhan ini sebagai curah pendapat dari peserta untuk memperoleh masukan berupa persoalan, aspirasi, usulan, solusi dan gagasan. 3) Penyebaran kuisioner pre-test sebelum penyuluhan dan post-test sesudah penyuluhan bertujuan untuk mengukur tingkat pemahaman masyarakat mengenai hak dan kewajiban masyarakat desa berdasarkan Undang-Undang Nomor 6 Tahun 2014 tentang Desa. 


\section{HASIL DAN PEMBAHASAN}

Berdasarkan hasil kegiatan penyuluhan hukum tentang Peningkatan Pemahaman Masyarakat Desa Tanjung Karang Kecamatan Kampar Kiri Hulu Kabupaten Kampar Berdasarkan Undang-Undang Nomor 6 Tahun 2014 Tentang Desa mengenai hak dan kewajiban masyarakat desa, terlihat pemahaman masyarakat dan pihak-pihak terkait meningkat sesuai dengan tujuan yang diharapkan. Peningkatan pemahaman masyarakat dapat dibuktikan dengan hasil jawaban isian kuesioner pre-test dan post-test mengenai hak dan kewajiban masyarakat berdasarkan Undang-Undang Desa.

Secara keseluruhan kegiatan pengabdian kepada masyarakat di Desa Tanjung Karang, Kecamatan Kampar Kiri Hulu, Kabupaten Kampar yang dilaksanakan pada tanggal 6 Januari 2020 di ruang pertemuan Kantor Desa Tanjung Karang, Kecamatan Kampar Kiri Hulu, Kabupaten Kampar berjalan dengan lancar dan sukses. Pengabdian dimulai pada pukul 13.00 WIB hingga 14.30 WIB sebanyak 30 (tiga puluh) orang peserta yang hadir pada kegiatan ini. Kegitaan pengabdian dilaksanakan dengan terlebih dahulu dibuka dengan kata sambutan oleh Kepala Desa Tanjung Karang Bapak Busrianto, S.H. Kepala desa mengucapkan terimakasih atas kesedian tim pengabdian dari Fakultas Hukum Universitas Lancang Kuning berkunjung dan memberikan ilmu kepada masyarakat desa Tnjung Karang. Sebelum materi di sampaikan terlebih dahulu dibagikan kuisioner yang nantinya akan menjadi bahan ukuran dalam peningkatan pemahaman masyarakat atas kegiatan yang dilaksanakan.

Kegiatan penyuluhan dimulai dengan menyampaikan materi tentang hak dan kewajiban masyarakat desa berdasarkan Undang-Undang Nomor 6 Tahun 2014 tentang desa yang disampaikan oleh Bapak Dr. Ardiansah, S.H., M.Ag., M.H. selaku ketua tim pengabdian kepada masyarakat selama lebih kurang 30 (tiga puluh) menit.

Agar kegiatan penyuluhan hukum ini bermanfaat bagi peserta, maka tim penyuluhan hukum menyampaikan materi serta membagikan materi yang disampaikan dalam bentuk hardcopy kepada masing-masing peserta agar peserta dapat lebih memahami tentang hak dan kewajiban mereka sebagai masyaraat Desa berdasarkan Undang-Undang Nomor 6 Tahun 2014 tentang Desa. Sehingga kedepan masyarakat Desa Tanjung Karang dapat memahami apa yang menjadi hak dan kewajiban mereka selaku masyarakat Desa.

Sebelum materi penyuluhan hukum disampaikan, terlebih dahulu dibagikann kuisioner pre-test untuk diisi peserta dan dikumpulkan sebelum penyampaian materi. Kemudian setelah materi disampaikan kembali dibagikan kuisioner post-test untuk mengukur tingkat pemahaman peserta dari materi yang disampaikan. Dari hasil kuisioner 
pre-test dan post-test terlihat peningkatan pemahaman peserta dalam menerima materi penyuluhan hukum.

Peningkatan pemahaman peserta penyuluhan hukum dapat terlihat dari hasil pre-test dan post-test sebagai berikut :

Pre Test:

\begin{tabular}{|c|c|c|c|}
\hline \multirow[t]{2}{*}{ No } & \multirow[t]{2}{*}{ Pertanyaan } & \multicolumn{2}{|c|}{ Pilihan } \\
\hline & & Benar & Salah \\
\hline 1 & $\begin{array}{l}\text { Apakah salah satu kewajiban masyarakat desa } \\
\text { menurut Pasal } 68 \text { ayat (2) Undang-Undang } \\
\text { Nomor } 6 \text { Tahun } 2014 \text { Tentang Desa? }\end{array}$ & $28 \%$ & $72 \%$ \\
\hline 2 & $\begin{array}{l}\text { Mendorong } \begin{array}{c}\text { terciptanya } \\
\text { penyelenggaraan }\end{array} \text { Pemerintahan } \\
\text { pelaksanaan Pembangunan Desa, pembinaan } \\
\text { kemasyarakatan Desa dan pemberdayaan } \\
\text { masyarakat Desa yang baik, ini adalah salah satu } \\
\text { kewajiban masyarakat desa. Terdapat dalam } \\
\text { Pasal, ayat dan butir berapakah dalam Undang- } \\
\text { Undang tentang Desa? }\end{array}$ & $6 \%$ & $94 \%$ \\
\hline 3 & $\begin{array}{l}\text { Apakah berpartisipasi dalam berbagai kegiatan } \\
\text { di Desa merupakan kewajiban dari masyarakat } \\
\text { Desa? }\end{array}$ & $81 \%$ & $19 \%$ \\
\hline 4 & $\begin{array}{l}\text { Apakah masyarakat Desa berhak melakukan } \\
\text { pemantauan terhadap pelaksanaan Pembangunan } \\
\text { Desa? }\end{array}$ & $81 \%$ & $19 \%$ \\
\hline 5 & $\begin{array}{l}\text { Masyarakat Desa berhak mendapatkan informasi } \\
\text { mengenai rencana dan pelaksanaan } \\
\text { Pembangunan Desa ini adalah salah satu bentuk } \\
\text { pemantauan dan pengawasan masyarakat Desa } \\
\text { terhadap Pembanguna Desa. Terdapat dalam } \\
\text { pasal dan ayat berapakah dalam Undang-Undang } \\
\text { desa? }\end{array}$ & $3 \%$ & $97 \%$ \\
\hline
\end{tabular}

Pos Test:

\begin{tabular}{|c|l|c|c|}
\hline No & \multicolumn{1}{|c|}{ Pertanyaan } & \multicolumn{2}{|c|}{ Pilihan } \\
\cline { 3 - 4 } & \multicolumn{1}{|c|}{ Benar } & Salah \\
\hline 1 & $\begin{array}{l}\text { Apakah salah satu kewajiban masyarakat desa } \\
\text { menurut Pasal 68 ayat (2) Undang-Undang } \\
\text { Nomor 6 Tahun 2014 Tentang Desa? }\end{array}$ & $100 \%$ & $0 \%$ \\
\hline 2 & $\begin{array}{l}\text { Mendorong terciptanya kegiatan } \\
\text { penyelenggaraan Pemerintahan Desa, } \\
\text { pelaksanaan Pembangunan Desa, pembinaan } \\
\text { kemasyarakatan Desa dan pemberdayaan } \\
\text { masyarakat Desa yang baik, ini adalah salah satu } \\
\text { kewajiban masyarakat desa. Terdapat dalam } \\
\text { Pasal, ayat dan butir berapakah dalam Undang- }\end{array}$ & & $0 \%$ \\
\hline
\end{tabular}




\begin{tabular}{|c|l|c|c|}
\hline & Undang tentang Desa ? & \\
\hline 3 & $\begin{array}{l}\text { Apakah berpartisipasi dalam berbagai kegiatan } \\
\text { di Desa merupakan kewajiban dari masyarakat } \\
\text { Desa? }\end{array}$ & $100 \%$ & $0 \%$ \\
\hline 4 & $\begin{array}{l}\text { Apakah masyarakat Desa berhak melakukan } \\
\text { pemantauan terhadap pelaksanaan Pembangunan } \\
\text { Desa? }\end{array}$ & $0 \%$ \\
\hline 5 & $\begin{array}{l}\text { Masyarakat Desa berhak mendapatkan informasi } \\
\text { mengenai rencana dan pelaksanaan } \\
\text { Pembangunan Desa ini adalah salah satu bentuk } \\
\text { pemantauan dan pengawasan masyarakat Desa } \\
\text { terhadap Pembanguna Desa. Terdapat dalam } \\
\text { pasal dan ayat berapakah dalam Undang-Undang } \\
\text { desa? }\end{array}$ & & $0 \%$ \\
\hline
\end{tabular}

Berdasarkan evaluasi melalui sebaran kuisioner dari jawaban peserta terlihat bahwa secara keseluruhan peserta telah memahami dari materi yang disampaikan dan bertambahnya wawasan tentang hak dan kewajiban sebagai masyarakat desa berdasarkan Undang-Undang Nomor 6 Tahun 2014 tentang Desa. Peningkatan pemahaman terlihat dari jawaban kuisioner post-test yang dimana jawaban keseluruhan peserta mencapai $100 \%$ artinya peserta menjawab benar seluruh pertanyaan setelah materi penyuluhan disampaikan.

Berikut ini adalah dokumentasi pada saat pelaksanaan Pengabdian Kepada Masyarakat yang dilakukan Tim dari Fakultas Hulum Universitas Lancang Kuning di Desa Tanjung Karang, Kecamatan Kampar Kiri Hulu, Kabupaten Kampar.

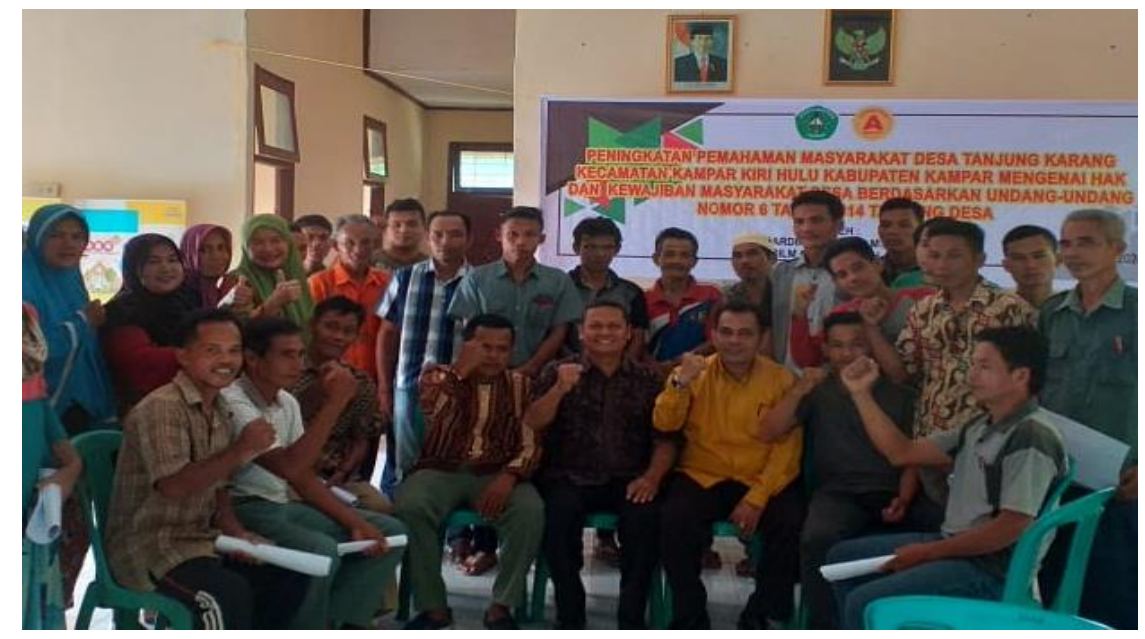

Gambar 1. Foto Bersama Kepala Desa Dan Seluruh Peserta Penyuluhan 


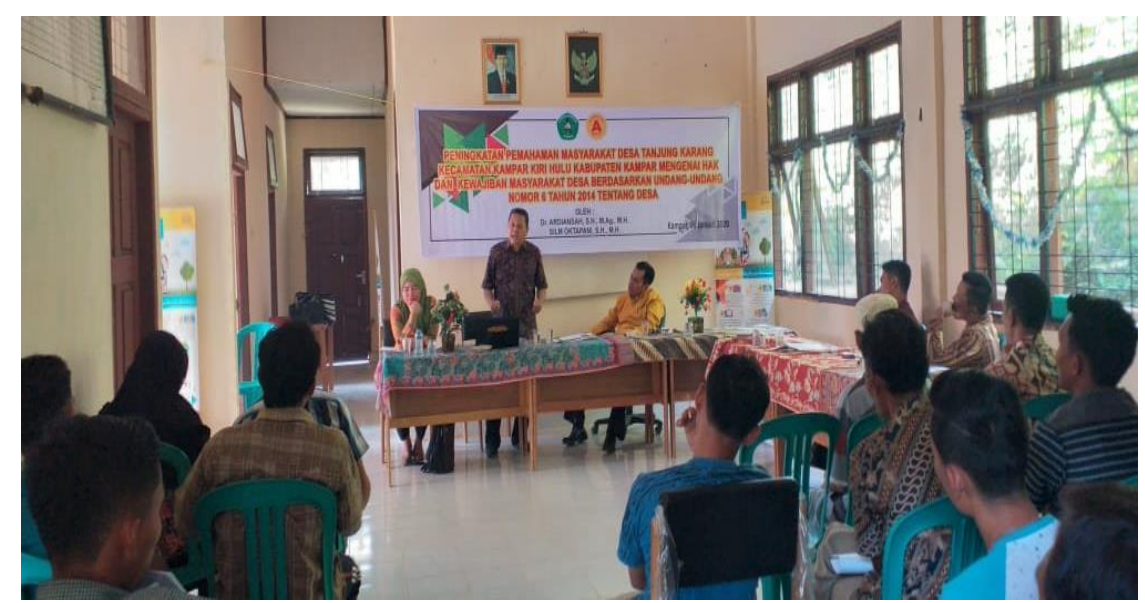

Gambar 2. Pemaparan Materi Oleh Dr. Ardiansah, S.H.,M.Ag., M.H.

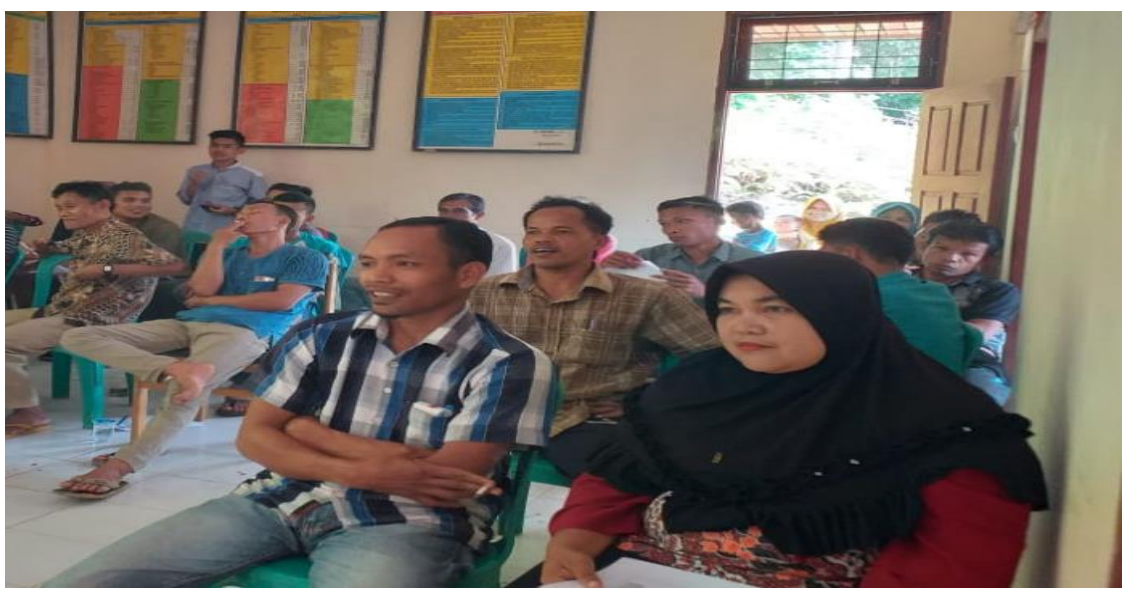

Gambar 3. Peserta Penyuluhan

\section{SIMPULAN}

Setelah dilaksanakannya rangkaian kegiatan pengabdian masyarakat maka dapat disimpulkan bahwa peserta dapat memahami tentang hak dan kewajiban masyarakat Desa berdasarkan Undang-Undang nomor 6 Tahun 2014 tentang Desa. Masyarakat desa Tanjung Karang memahami bahwa mereka sebagai masyarakat berhak meminta dan mendapatkan informasi dari Pemerintah Desa serta mengawasi kegiatan penyelenggaraan Pemerintahan Desa, Pelaksanaan Pembangunan Desa, Pembinaan Kemasyarakatan Desa, dan pemberdayaan masyarakat desa. Berpartisipasi dalam berbagai kegiatan di desa merupakan suatu kewajiban yang harus di lakukan oleh masyarakat desa berdasrkan Undang-Undang Nomor 6 Tahun 2014 tentang Desa.

\section{SARAN}

Kegiatan penyuluhan hukum kepada masyarakat Desa ini harus selalu dilaksankan secara rutin terkhusus masyarakat Desa yang berada di Provinsi Riau agar masyarakat Desa yang jauh dari informasi terutama Desa-desa yang sulit akan transportasi, belum terjangkau oleh aliran listrik dan alat komunikasi harus lebih sering diberikan informasi 
agar mereka bisa mendapatkan informasi sama dengan masyarakat yang berada perkotaan.

\section{UCAPAN TERIMAKASIH}

Tim Pengabdian kepada Masyarakat mengucapkan terimakasih kepada Dekan Fakultas Hukum Universitas Lancang Kuning, Ketua Unit Penelitian dan Pengabdian Masyarakat Fakultas Hukum Universitas Lancang Kuning, Ketua Lembaga Penelitian dan Pengabdian kepada Masyarakat Universitas Lancang Kuning, Kepala dan perangkat Desa Tanjung Karang, Ketua Rukun Tetangga, Ketua Rukun Warga Ujung Batu Timur, Warga Desa Tanjung Karang dan seluruh pihak yang telah terlibat dalam terselenggaranya kegiatan Pengabdian kepada Masyarakat ini.

\section{DAFTAR PUSTAKA}

Aritonang, Dinoroy M. (2015). Kebijakan Desentralisasi Untuk Desa Dalam UndangUndang Nomor 6 Tahun 2014 Tentang Desa ( Decentralization Policy For Village In Law Number 6 Of 2014 On Village ). Jurnal Legislasi, 12 (3), 1-28

Eko, sutoro. (2014). Kedudukan Dan Kewenangan Desa. Yogyakarta:FPPB.

Kushandajani. (2015). Desain Implementasi Penyelenggaraan Pemerintahan Desa Berdasarkan UU No. 6 Tahun 2014 Tentang Desa Di Kabupaten Semarang. Politika, 6 (2), 63-73. https://doi.org/10.14710/politika.6.2.2015.63-73

—. (2015). Implikasi UU Nomor 6 Tahun 2014 Tentang Desa Terhadap Kewenangan Desa. Yustisia Jurnal Hukum, 4 (2), 369-96. https://doi.org/10.20961/yustisia.v92i0.3820

Mardison. (2012). Membangun Desa. Jurnal Resvinding, 53 (9), 1689-99. https://doi.org/10.1017/CBO9781107415324.004

Phahlevy, Rifqi Ridlo. (2016). Pergeseran Kebijakan Tata Pemerintahan Desa Di

Kabupaten Sidoarjo Pasca UU Nomor 6 Tahun 2014, Jurnal Kosmik Hukum, 16 (1), 42-63. http://jurnalnasional.ump.ac.id/index.php/KOSMIK/article/view/1274

Pitono, Andi. (2016). Penguatan Pemerintahan Desa Dan Kelurahan Menuju Pembangunan Berkelanjutan Dalam Rangka Peningkatan Kesejahteraan Masyarakat, Jurnal Politikologi, 3 (1), 27-38.

Ra'is, Dekki Umamur. (2014). Kebijakan Pemberdayaan Masyarakat Dalam Perspektif Asas Rekognisi Dan Subsidiaritas Undang-Undang Desa Nomor 6 Tahun 2014, Jurnal Reformasi, 7 (1), 29-46. https://doi.org/10.33366/rfr.v7i1.695

Sugiman, Sugiman. (2018). Pemerintahan Desa, Jurnal Binamulia Hukum, 7 (1), 82-95. https://doi.org/10.37893/jbh.v7i1.16 
Theresia, Aprilia, Dkk. (2014). Pembangunan Berbasis Masyarakat. Bandung: Alfabeta.

Timotius, Richard. (2018). Revitalisasi Desa Dalam Konstelasi Desentralisasi Menurut Undang-Undang Nomor 6 Tahun 2014 Tentang Desa, Jurnal Hukum \& Pembangunan, 48 (2), 323. https://doi.org/10.21143/jhp.vol48.no2.1666 